\title{
Evidence for Role of Hydroxyl Radical in Complement and Neutrophil-dependent Tissue Injury
}

\author{
Peter A. Ward, Gerd O. Till, Robin Kunkel, and Charles Beauchamp, \\ Department of Pathology, The University of Michigan Medical School, Ann \\ Arbor, Michigan 48109; Department of Medicine, Veteran's Administration \\ Hospital, Ann Arbor, Michigan 48105
}

\begin{abstract}
A B S T R A C T Using our recently described model of acute lung injury in rats after systemic activation of complement by cobra venom factor (CVF), we demonstrated that pretreatment of animals with human milk apolactoferrin (in its native or derivatized form), but not iron-saturated lactoferrin, provides significant protection against complement- and neutrophil-mediated lung injury. The synthetic iron chelator deferoxamine mesylate also affords protection from lung injury. The protective effects of apolactoferrin are not related to a blocking of CVF-induced complement activation. We also demonstrated that infusion of ionic iron, especially $\mathrm{Fe}^{3+}$, greatly potentiates lung vascular injury after systemic complement activation. Finally, protection from lung injury occurs in animals pretreated with the potent scavenger of hydroxyl radicals $\left(\mathrm{OH}^{*}\right)$, dimethyl sulfoxide. Based on transmission electron microscopy, CVF-treated rats show leukoaggregates and endothelial cell destruction in interstitial pulmonary capillaries, along with intraalveolar hemorrhage and fibrin deposition. In animals protected with apolactoferrin, deferoxamine mesylate, or dimethyl sulfoxide, the morphological studies reveal leukoaggregates but no endothelial cell damage, hemorrhage, or fibrin deposition. These data support the concept that tissue injury that is complement and neutrophil dependent may be related to generation of $\mathrm{OH}^{\cdot}$ derived from $\mathrm{H}_{2} \mathrm{O}_{2}$ after leukocytic activation.
\end{abstract}

\section{INTRODUCTION}

Tissue damage associated with the acute inflammatory response, such as occurs after deposition of immune complexes, has been linked to a requirement for the complement system as well as neutrophils (1). Complement activation products, namely C5a, serve as che-

Received for publication 18 March 1983 and in revised form 25 May 1983. moattractants to bring about accumulation of neutrophils within tissues (2). At the same time, there is evidence that chemotactic peptides such as C5a can stimulate neutrophils in a manner that results in the generation of a family of toxic oxygen products, including superoxide anion $\left(\mathrm{O}_{2}^{+}\right), \mathrm{H}_{2} \mathrm{O}_{2}$, and other products such as the hydroxyl radical $\left(\mathrm{OH}^{*}\right)$ (reviewed, 3 ). After deposition of immune complexes and subsequent complement activation within lung alveoli, significant protection from injury can be accomplished by treatment of animals with catalase, suggesting that leukocytic production of $\mathrm{H}_{2} \mathrm{O}_{2}$ is a key event (4).

In another model of acute lung injury, intravascular activation of complement after infusion of the $\mathrm{C} 3 \mathrm{ac}$ tivator isolated from cobra venom results in acute lung injury with focal damage of endothelial cells lining the interstitial capillaries. The pathogenesis of this injury seems to involve the following steps: appearance of C5a in plasma, leukocytic activation, neutropenia, leukoaggregation, sequestration of neutrophils within the lung interstitial capillaries, and, finally, endothelial cell damage that can be blocked by the infusion of catalase and superoxide dismutase (5).

In the studies to be presented, we demonstrate that, in the model of systemic complement activation, acute lung injury can be greatly diminished if interventions are used that reduce the availability of iron ions. Conversely, infusion of ionic iron potentiates the tissue damage. In addition, dimethyl sulfoxide (DMSO), ${ }^{1}$ a potent scavenger of hydroxyl radical, protects against the tissue injury. These data support an increasing body of evidence suggesting that iron-catalyzed conversion of leukocyte-produced $\mathrm{H}_{2} \mathrm{O}_{2}$ into the hydroxyl radical $\left(\mathrm{OH}^{*}\right)$ is a critical step in events leading to acute tissue injury.

\footnotetext{
${ }^{1}$ Abbreviations used in this paper: C5a, complement 5a; $\mathrm{CH}_{50}$, total hemolytic complement; CVF, cobra venom factor; DMSO, dimethyl sulfoxide; PEG, polyethylene glycol.
} 


\section{METHODS}

Animal model of lung injury. As recently described (5), pathogen-free adult $(250 \mathrm{~g})$, male Long Evans rats were used for the studies to be described. Approximately 4.0 units (50 $\mu \mathrm{g}$ protein) of cobra venom factor (CVF) were injected intravenously along with $5 \mu \mathrm{g}{ }^{125} \mathrm{I}$-bovine serum albumin. Either radiolabeled rat ${ }^{125} \mathrm{I}$-IgG or ${ }^{125} \mathrm{I}$-bovine serum albumin can be used as markers of increased vascular permeability $(4,5)$ in lung, although precise comparisons between the two as markers of permeability have not been carried out. Animals were anesthetized with ketamine hydrochloride (Parke Davis and Co., Morris Plains, NJ) and exsanguinated $30 \mathrm{~min}$ later via the vena cava inferior. The lung vasculature was then perfused through the right cardiac ventricle with 10 $\mathrm{ml}$ phosphate-buffered saline ( $\mathrm{pH}$ 7.4). The lungs were removed and the amount of radioactivity remaining within the tissue assessed with a gamma scintillation counter. Lung damage was defined by the increased lung vascular permeability, as determined by the ratio of radioactivity present within lung tissue and the amount of radioactivity present in $1.0 \mathrm{ml}$ venous blood obtained when the animals were killed. In a control animal, the ratio (defined as the permeability value) usually fell between 0.15 and 0.25 , whereas in the case of lung injury this ratio could increase to values as high as $\mathbf{1 . 5 5}$. Protection from lung injury was determined by the following equation:

Percent protection

$$
=100 \times\left[\begin{array}{c}
\text { (test permeability value) } \\
1-\frac{- \text { (saline permeability value) }}{(\text { positive control permeability value) }} \\
- \text { (saline permeability value) }
\end{array}\right]
$$

Details of this animal model have been recently published (5). When animals were subjected to various therapeutic interventions, the agents were injected intravenously together with CVF or intraperitoneally $10 \mathrm{~min}$ before vascular infusion of CVF.

Preparation and characterization of lactoferrin. Lactoferrin was prepared from human breast milk by the procedures of Bläckberg and Hernell (6). Briefly, the fat-rich fraction was removed by flotation centrifugation. The preparation was then treated with $\mathrm{HCl}$ to remove casein and subjected to chromatographic separation in a heparin-Sepharose column. To obtain apolactoferrin (iron free), the lactoferrin preparation was extensively dialyzed against 0.1 $M$ citric acid to remove bound iron. The iron-saturated form of lactoferrin was prepared by the addition of $0.025 \mu \mathrm{mol}$ of $\mathrm{Fe}^{3+} / \mathrm{mg}$ protein according to the procedure of Masson and Heremans (7). Nonbound iron was removed by dialysis of the lactoferrin in phosphate-buffered saline. By the ferrozine colorimetric method, the apolactoferrin preparation contained $80 \mathrm{ng} \mathrm{Fe} \mathrm{F}^{3+} / \mathrm{mg}$ apolactoferrin, while the iron-saturated preparation contained $1,120 \mathrm{ng} \mathrm{Fe}^{3+} / \mathrm{mg}$ lactoferrin. When analyzed by in vivo clearance studies, the lactoferrin preparations were first radiolabeled with ${ }^{125} \mathrm{I}$ by the lactoperoxidase method (8). Clearance studies were accomplished by intravenous injection (via a penile vein) of $\sim 5 \mu \mathrm{g}{ }^{125} \mathrm{I}$ labeled apolactoferrin and frequent samples of blood were obtained from tail veins. Derivatized apolactoferrin was accomplished by treatment of apolactoferrin with carbonyldiimidazole-activated polyethylene glycol (PEG) of 4,000 average molecular weight by procedures recently described (9).
Interventional therapy. Several interventions were used. When preparations of lactoferrin were used, they were injected intravenously with CVF and ${ }^{125}$ I-bovine serum albumin. For the nonderivatized preparations, unless otherwise indicated, $1.0 \mathrm{mg}$ apolactoferrin or iron-saturated lactoferrin were used. For the derivatized lactoferrin preparations, $100 \mu \mathrm{g}$ were used. DMSO was obtained from the Fisher Scientific Co. (Fair Lawn, NJ); $1.0 \mathrm{ml}$ was injected by the intraperitoneal route $10 \mathrm{~min}$ before the intravenous injection of CVF. $\mathrm{Fe}\left(\mathrm{NH}_{4}\right)_{2}\left(\mathrm{SO}_{4}\right)_{2}$ and $\mathrm{FeCl}_{3}$ were dissolved in sterile saline. Varying amounts of the iron salts were injected intravenously together with CVF. Deferoxamine mesylate was purchased from Ciba-Geigy Corp. (Summit, NJ) and injected intravenously together with CVF. The total volume of material injected intravenously was always maintained at $0.5 \mathrm{ml}$.

Measurement of complement. Total serum complement activity, expressed as $\mathrm{CH}_{50}$ units, was measured by the standard hemolytic assay with antibody-coated sheep erythrocytes (1). Estimation of C3 conversion was accomplished by crossed immunoelectrophoresis (10). Planimetry was used to determine the amounts of native and converted $\mathrm{C} 3$, the latter representing $\mathrm{C} 3 \mathrm{~b}$.

Blood neutrophil counts. These were determined in the usual fashion with blood samples from tail veins delivered into acetic acid, followed by cell counts as assessed in hemocytometers.

Morphometric studies of lung. Plastic embedded sections ( $1 \mu \mathrm{m}$ thickness) of lung tissue stained with toluidine blue were obtained from animals injected intravenously $30 \mathrm{~min}$ before fixation of lungs with glutaraldehyde. Agents injected intravenously included: saline, CVF, CVF and apolactoferrin, as described in the text. 21 different interstitial capillaries and alveoli from CVF-treated rats were examined by morphometry, as were six similar structures from salinetreated rats and 15 from rats treated with CVF and apolactoferrin (which was used in amounts shown to be protective for lung injury). These structures had been randomly selected for analysis with a Zeiss Photomicroscope II with a $\times 40$ objective (Carl Zeiss, Inc., New York). This instrument was connected electronically to a high resolution television camera, which, in turn, was connected to a Zeiss Video Plan containing a television screen. The instrument was programmed to permit measurement of $(a)$ length of endothelial surfaces of interstitial capillaries, $(b)$ preparation of this surface involved with bleb formation, $(c)$ number of neutrophils within capillaries, $(d)$ length of alveolar surfaces, and $(e)$ numbers of erythrocytes within alveolar compartments. Areas to be measured were outlined on the television screen with an electronic wand and the measurements fed into a computer for analysis.

\section{RESULTS}

Characterization of purified lactoferrin. Preparations of apolactoferrin were examined by acrylamide gel electrophoresis in the presence of sodium dodecyl sulfate. The results of a typical experiment are shown in Fig. 1. Apolactoferrin appeared, as expected, in the 77,000-D position. To determine the clearance rates of apolactoferrin and derivatized (by PEG) apolactoferrin, we measured the rates of disappearance (clearance) of ${ }^{125} \mathrm{I}$-labeled preparations from rat blood. As shown in Fig. 2, the nonderivatized preparation of lactoferrin had an exceedingly rapid disappearance rate, 


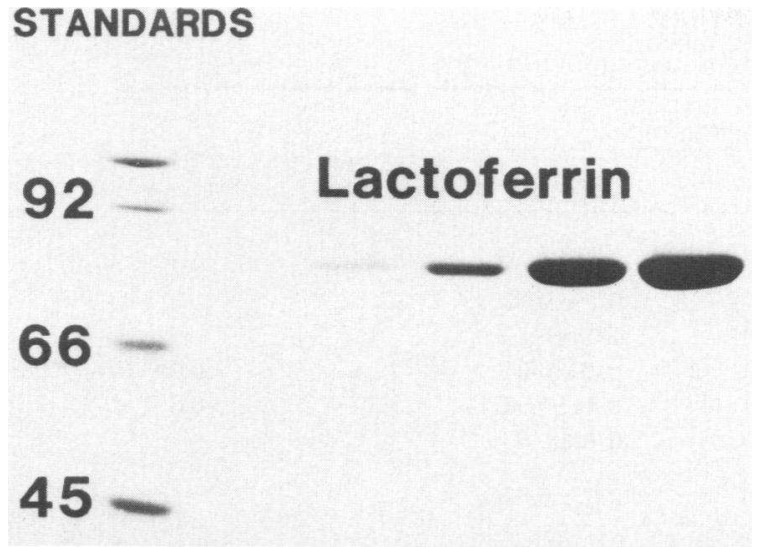

FIgURE 1 Polyacrylamide electrophoretic analysis (in sodium dodecyl sulfate) of apolactoferrin. Reference standards are also shown. The numbers refer to kilodaltons. Apolactoferrin occupies a position consistent with a molecular mass of $77,000 \mathrm{D}$

with a $t_{1 / 2}$ value of $<2 \mathrm{~min}$, whereas the derivatized preparation had a prolonged retention value in the circulation, with an estimated $t_{1 / 2}$ value of $18 \mathrm{~h}$.

Dose response for protective effects of apolactoferrin. We determined a dose-response relationship of apolactoferrin for protection against acute lung injury after the vascular infusion of 4 units of CVF. This treatment results in systemic activation of the complement system, neutrophil activation, and injury (which is catalase sensitive) of lung vascular endothelial cells (5). As shown in Fig. 3, protection from acute

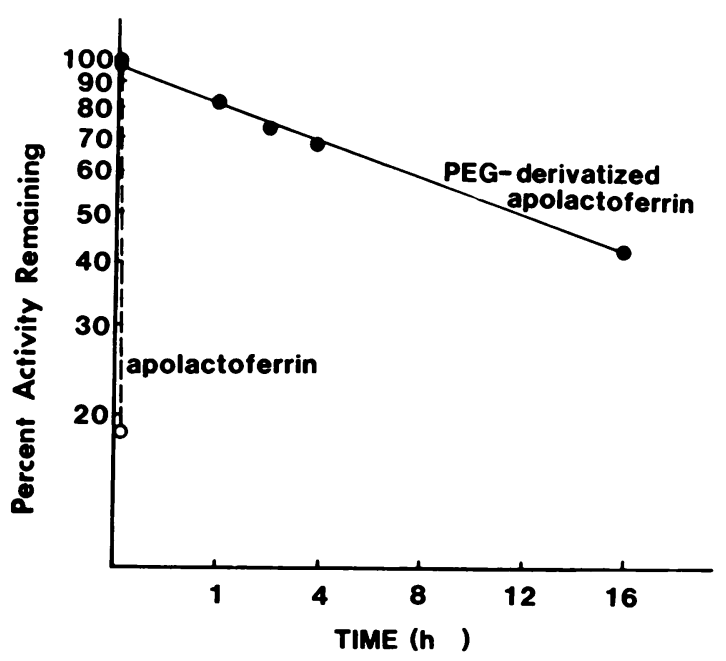

Figure 2 Clearance of lactoferrin from rat blood. Turnover studies in rats of apolactoferrin and PEG-derivatized apolactoferrin. The estimated clearance rates $\left(t_{1 / 2}\right)$ for these two preparations are $<2 \mathrm{~min}$ and $18 \mathrm{~h}$, respectively.

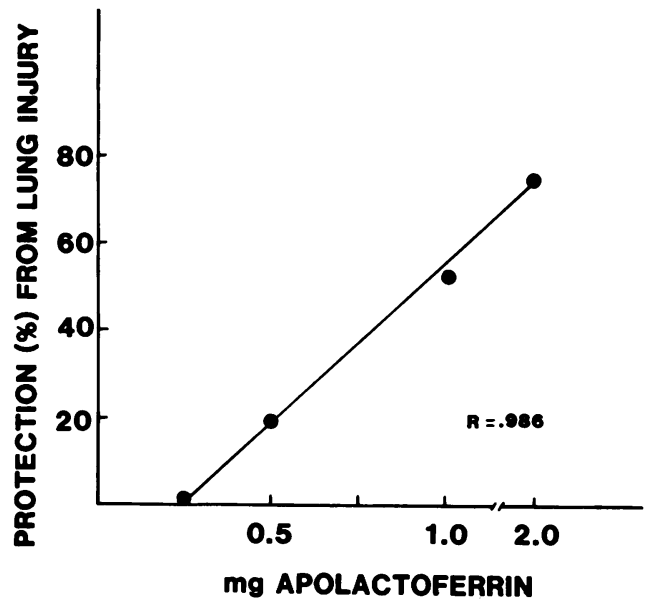

Figure 3 Dose response for lactoferrin-induced protection from lung injury. Protective effects of apolactoferrin on acute lung injury after systemic complement activation. Protection is a function of the dose of apolactoferrin infused intravenously.

lung injury, as measured by changes in lung permeability, was directly proportional to the amount of apolactoferrin infused with the CVF. No protection was found with $0.25 \mathrm{mg}$ apolactoferrin. However, when $0.5 \mathrm{mg}$ was used, $20 \%$ protection was found; 1.0 $\mathrm{mg}$ gave $57 \%$ protection, and $2.0 \mathrm{mg}$ produced $72 \%$ protection. (In this series of experiments, the mean lung permeability value of the unprotected animals was 0.87.) Thus, apolactoferrin infused with the CVF provided protection, in a dose-dependent manner, against acute lung injury accompanying systemic complement activation. The coefficient of correlation was 0.986 .

Comparison of protective effects of apolactoferrin and iron-saturated lactoferrin. The results from three different experiments are described in Table $I$. In experiment $A$, the intravenous infusion $(0.5 \mathrm{ml})$ of saline and ${ }^{125}$ I-bovine serum albumin resulted in a base-line value for lung permeability of $0.18 \pm 0.02$. As expected, the infusion of 4.0 units of CVF into each of three rats resulted in abrupt lung injury, with a mean lung permeability value of $1.00 \pm 0.13$. In parallel experiments, the simultaneous infusion of CVF and $1.0 \mathrm{mg}$ human apolactoferrin resulted in a great attenuation of the lung injury, with a mean permeability value in four animals of $0.39 \pm 0.04$, indicating $74 \%$ protection from the lung injury. In contrast, when ironsaturated lactoferrin was used, there was much less protection (20\%) against the lung injury, with a mean permeability value of $0.84 \pm 0.03$. The infusion into two rats of $1.0 \mathrm{mg}$ apolactoferrin alone did not result in an increase in lung permeability $(0.12 \pm 0.05)$, indicating that apolactoferrin does not itself produce lung 
TABLE I

Lactoferrin-induced Protection from Acute Lung Injury

\begin{tabular}{|c|c|c|c|c|c|}
\hline \multirow{2}{*}{$\begin{array}{l}\text { Experi- } \\
\text { ment }\end{array}$} & \multirow[b]{2}{*}{ Material injected ${ }^{\bullet}$} & \multicolumn{2}{|c|}{ Lung permeability } & \multirow{2}{*}{$\begin{array}{c}\text { Protection } \\
\text { from lung injury }\end{array}$} & \multirow[b]{2}{*}{ Significance } \\
\hline & & Individual values & Mean \pm SEM & & \\
\hline & & & & $\%$ & $P$ \\
\hline \multirow[t]{5}{*}{ A } & Saline & $0.20,0.17,0.10,0.23$ & $0.18 \pm 0.02$ & & \\
\hline & CVF & $0.76,1.23,1.00$ & $1.00 \pm 0.13$ & & \\
\hline & $\mathrm{CVF}+$ apolactoferrin & $0.49,0.34,0.33,0.29$ & $0.39 \pm 0.04$ & 74 & $<0.005$ \\
\hline & CVF + iron-saturated lactoferrin & $0.79,0.90,0.84$ & $0.84 \pm 0.03$ & 20 & $>0.3$ \\
\hline & Apolactoferrin & $0.17,0.07$ & $0.12 \pm 0.05$ & & \\
\hline \multirow[t]{5}{*}{ B } & CVF & $0.83,0.87,0.76$ & $0.82 \pm 0.02$ & & \\
\hline & $\mathrm{CVF}+$ apolactoferrin & $0.40,0.36,0.42,0.52$ & & & \\
\hline & (derivatized) & $0.70,0.29,0.35$ & $0.43 \pm 0.05$ & 61 & $<0.005$ \\
\hline & $\begin{array}{l}\text { CVF + iron-saturated lactoferrin } \\
\text { (derivatized) }\end{array}$ & $0.78,0.90$ & $\begin{array}{l}0.84 \pm 0.04 \\
0.81 \pm 0.08\end{array}$ & 0 & $>0.7$ \\
\hline & CVF + bovine serum albumin & $0.73,0.88$ & $0.81 \pm 0.08$ & $<2$ & $>0.8$ \\
\hline \multirow[t]{4}{*}{$\mathrm{C}$} & CVF & $1.82,1.36,1.47$ & $1.55 \pm 0.18$ & & \\
\hline & CVF + apolactoferrin & $0.52,0.66,0.71,0.45$ & & & \\
\hline & (derivatized) & $0.79,0.56$ & $0.62 \pm 0.04$ & 68 & $<0.001$ \\
\hline & $\begin{array}{l}\mathrm{CVF}+\text { iron-saturated lactoferrin } \\
\quad \text { (derivatized) }\end{array}$ & $1.05,1.20,1.08,1.09$ & $1.10 \pm 0.03$ & 26 & $<0.02$ \\
\hline
\end{tabular}

- Doses used: CVF, 4.0 units; apolactoferrin and iron-saturated lactoferrin, $1.0 \mathrm{mg}$; PEG derivatives of apolactoferrin and iron-saturated lactoferrin, $100 \mu \mathrm{g}$; bovine serum albumin, $2.0 \mathrm{mg}$.

$\ddagger$ When compared with values obtained in animals treated with CVF alone.

injury. Similarly, the infusion into two rats of $1.0 \mathrm{mg}$ iron-saturated lactoferrin failed to produce lung injury in the absence of CVF (lung permeability value of $0.09 \pm 0.03)$.

In experiments $B$ and $C$, preparations of lactoferrin derivatized by PEG were used at much lower doses $(100 \mu \mathrm{g})$. In the former experiment, derivatized apolactoferrin conferred $61 \%$ protection from lung injury, whereas no protection was found with the use of derivatized lactoferrin that was iron saturated. That the protective effects of apolactoferrin were specific was shown by this result as well as by the finding that infusion of a mixture of CVF and bovine serum albumin (which has a molecular weight similar to apolactoferrin) failed to produce protection from lung injury. The results in experiment $C$ were confirmatory of those of experiment B: $68 \%$ protection from lung injury occurred with the derivatized preparation of apolactoferrin, whereas when the same preparation was iron saturated, only $26 \%$ protection from lung injury occurred. These data indicate that either relatively high doses of nonderivatized apolactoferrin or much lower doses of derivatized apolactoferrin will confer significant protection against acute lung injury after systemic complement activation, whereas ironsaturated preparations of either form of lactoferrin have little or no protective function.
C3 conversion in protected and nonprotected animals. To determine whether protection against lung injury afforded by treatment of rats with apolactoferrin could be attributed to a blocking of complement activation after infusion of CVF, sera from rats treated with a variety of different materials, as described in Table I, were analyzed for evidence of C3 conversion by means of crossed immunoelectrophoresis. An example of this technique is shown in Fig. 4, where native and converted $\mathrm{C} 3(\mathrm{C} 3 \mathrm{~b})$ are demonstrated. As

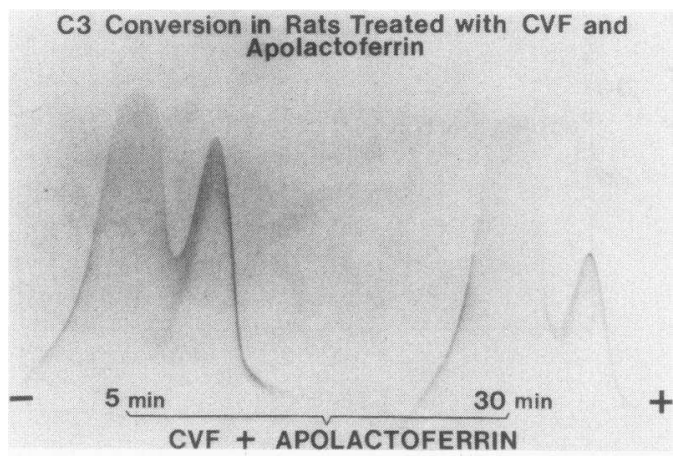

Figure 4 Crossed immunoelectrophoretic analysis of serum $\mathrm{C} 3$ at 5 and $30 \mathrm{~min}$ after infusion of CVF into rats. Converted C3 (C3b) appears in the anodal position of each profile. 
shown in Table II, sera from animals treated with saline revealed $<11 \%$ converted $\mathrm{C} 3$ at 5 and $30 \mathrm{~min}$ after vascular infusion of saline. (This low level of C3 conversion appears to represent an artifact, since sera taken from untreated rats consistently showed 5-10\% converted C3, probably the result of conversion occurring during in vitro manipulation of blood and serum). In animals injected with CVF, $45.3 \%$ of C3 appeared in the converted form at $5 \mathrm{~min}$, declining to $36.4 \%$ at $30 \mathrm{~min}$. In animals also treated with apolactoferrin under conditions that afforded protection from acute lung injury (Table I), virtually identical amounts of converted C 3 were found at the same intervals of time. In animals receiving CVF together with iron-saturated lactoferrin, $49.1 \%$ of the $\mathrm{C} 3$ appeared in the converted form at $5 \mathrm{~min}$, whereas $43.1 \%$ was found at the 30 -min interval. These data indicate that the protective effects of apolactoferrin are not associated with a blocking of the activation and conversion of C3 after infusion of CVF.

In additional studies, fresh rat serum was treated in vitro with CVF in the presence or absence of apolactoferrin, or iron-saturated lactoferrin, or with preparations of lactoferrin alone. Residual $\mathrm{CH}_{50}$ values were then measured. As the data in Table III indicate, addition of CVF to rat serum abolished measurable $\mathrm{CH}_{50}$ levels. The coincidental addition of apolactoferrin did not interfere with this loss of activity. The addition of lactoferrin alone (the apo form or the iron-saturated form) had a slight inhibitory effect (16\%) on $\mathrm{CH}_{50}$ levels in rat serum. The reason for this slight reduction in serum $\mathrm{CH}_{50}$ levels in the presence of apolactoferrin is unknown. In companion studies, normal rat serum C3 was examined by crossed immunoelectrophoresis

TABLE II

Lack of Effect of Apolactoferrin on In Vivo Conversion of C3

\begin{tabular}{|c|c|c|c|}
\hline \multirow[b]{2}{*}{ Material injected ${ }^{\bullet}$} & \multirow[b]{2}{*}{ Time } & \multicolumn{2}{|c|}{ Status of $\mathrm{C} 3$} \\
\hline & & Native & $\mathrm{C} 3 \mathrm{~b}$ \\
\hline & $\min$ & & \\
\hline \multirow[t]{2}{*}{ Phosphate-buffered saline } & 5 & 89.1 & 10.9 \\
\hline & 30 & 91.4 & 8.6 \\
\hline \multirow[t]{2}{*}{ CVF } & 5 & 54.7 & 45.3 \\
\hline & 30 & 63.6 & 36.4 \\
\hline \multirow[t]{2}{*}{$\mathrm{CVF}+$ apolactoferrin } & 5 & 54.1 & 45.9 \\
\hline & 30 & 65.9 & 34.1 \\
\hline \multirow{2}{*}{$\begin{array}{l}\text { CVF + iron-saturated } \\
\text { lactoferrin }\end{array}$} & 5 & 50.9 & 49.1 \\
\hline & 30 & 56.9 & 43.1 \\
\hline
\end{tabular}

- Where used, 4 units CVF, $1.0 \mathrm{mg}$ lactoferrin, and iron-saturated lactoferrin were injected in a total volume of $0.5 \mathrm{ml}$.
TABLE III

Residual $\mathrm{CH}_{50}$ Values after In Vitro Incubation of Rat Serum

\begin{tabular}{lc}
\hline \multicolumn{1}{c}{ Material added to serum } & Residual $\mathrm{CH}_{\mathbf{s o}}$ \\
\hline None & 66 \\
$\mathrm{CVF}^{\circ}$ & $<4$ \\
$\mathrm{CVF}+$ apolactoferrin $\ddagger$ & $<4$ \\
$\mathrm{CVF}+$ iron-saturated lactoferrin & $<4$ \\
Apolactoferrin & 52 \\
Iron-saturated lactoferrin & 54 \\
\hline
\end{tabular}

- $50 \mu \mathrm{l} \mathrm{CVF} \mathrm{(4} \mathrm{units)} \mathrm{was} \mathrm{added} \mathrm{to} 100 \mu \mathrm{l}$ fresh rat serum and the mixture incubated at $37^{\circ} \mathrm{C}$ for $30 \mathrm{~min}$

$\ddagger$ When used, $100 \mu \mathrm{g}$ apolactoferrin or iron-saturated lactoferrin were added to serum and the mixture incubated as described above.

in the presence or absence of apolactoferrin $(1.0 \mathrm{mg} /$ $\mathrm{ml}$ serum). There was $9.1 \% \mathrm{C} 3$ in the converted form in the absence of apolactoferrin; in its presence, $9.6 \%$ of C3 appeared in the converted form. Thus, the addition to serum of relatively high concentrations of apolactoferrin did not result in complement activation. These data, together with the fact that vascular infusion into the rat of $1.0 \mathrm{mg}$ of apolactoferrin did not result in acute lung injury (Table I, experiment A), suggest that the protective effects of apolactoferrin on complement-mediated acute lung injury are not the result of apolactoferrin interfering with activation of the complement system by CVF or due to its induction of a consumptive depletion of the complement system.

In vivo effects of lactoferrin on leukocyte levels. Because of some reports indicating that infusion of leukocytic lactoferrin can cause a neutropenia (11), it was important to determine whether this could be related to the protective effects of lactoferrin on complement-mediated acute lung injury, since neutrophils are known to play a key role in this reaction (5). As shown in Fig. 5, blood neutrophil counts were obtained after intravenous infusion of sterile saline, apolactoferrin, or iron-saturated lactoferrin $(2.0 \mathrm{mg})$. For each of the three reagents used, two animals were used per group. In each of the three groups, the absolute neutrophil count fell to $\sim 50 \%$ of the starting value. In animals treated with saline or with apolactoferrin, the neutrophil counts returned to the pretreatment values within the first 5-10 min, whereas the animals treated with iron-saturated lactoferrin showed a persistent increase (doubling) in neutrophil counts after the first $5 \mathrm{~min}$. The presence of $1.0 \mathrm{mg}$ apolactoferrin $/ \mathrm{ml}$ suspension of rat neutrophils does not interfere with their chemotactic response to zymosan-activated serum (data not shown). These data indicate that the effects of lactoferrin preparations on levels of circulating neutrophils do not appear to relate to the protective effects 


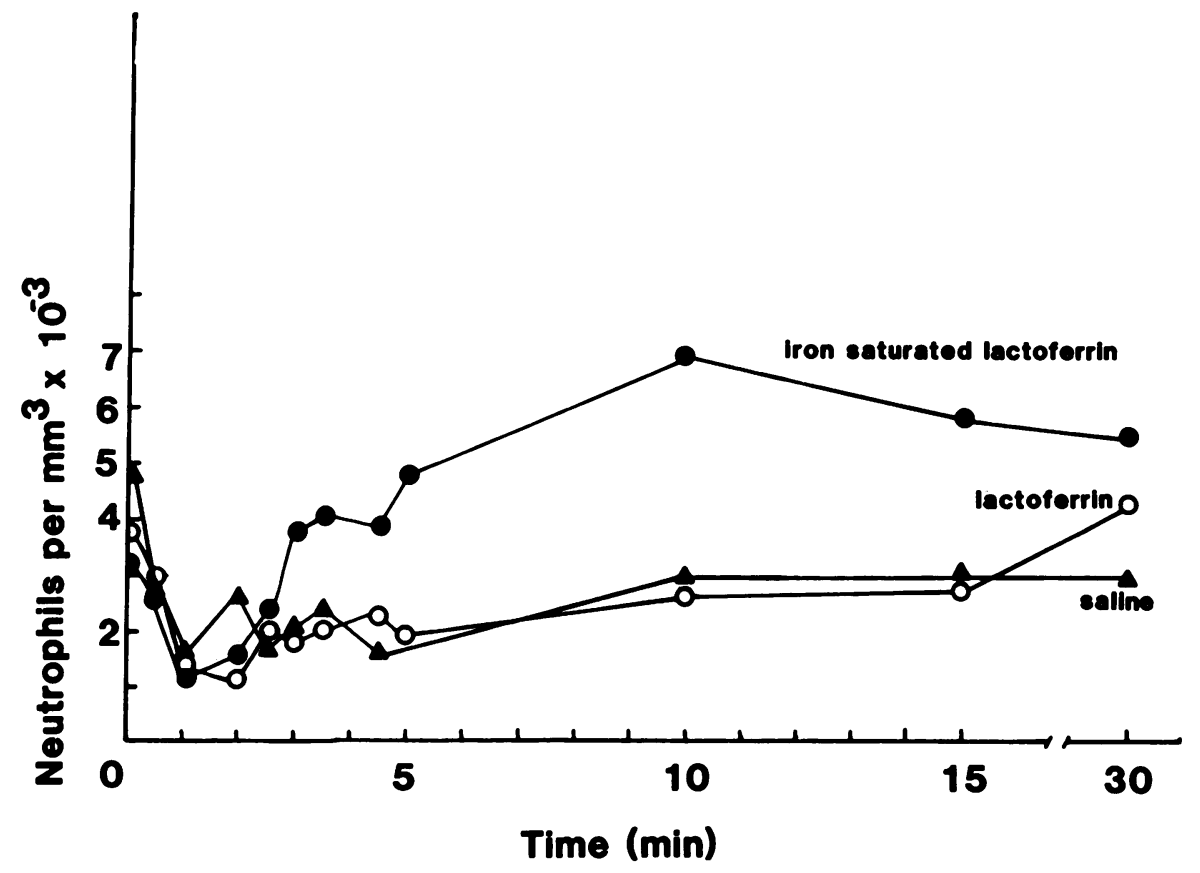

FIGURE 5 Peripheral blood neutrophil counts in animals treated with various preparations of lactoferrin. The protective preparation of lactoferrin ( $2 \mathrm{mg}$ apolactoferrin) had approximately the same effects on changes in levels of neutrophils as a saline infusion.

of lactoferrin on lung injury after systemic complement activation.

Protection from CVF-induced lung injury by deferoxamine mesylate. In view of the data showing protective effects of apolactoferrin on CVF-induced acute lung injury but not with iron-saturated lactoferrin (Table I), additional studies were carried out with the synthetic ferric ion chelator deferoxamine mesylate. This material was injected intravenously together with CVF. As demonstrated in Fig. 6, there was a direct relationship between the amount of deferoxamine infused and the protection from acute lung injury. The dose of deferoxamine causing $50 \%$ of protection against lung injury under the conditions used was $1.0 \mathrm{mg} / \mathrm{rat}$. That the protective effects of deferoxamine were not associated with a blocking of complement activation was shown by the fact that residual serum $\mathrm{CH}_{50}$ values in the sera of all animals treated with $\mathrm{CVF}$ and deferoxamine were $<4$ units $/ \mathrm{ml} 30 \mathrm{~min}$ after infusion of CVF, similar to the values obtained in animals receiving CVF in the absence of deferoxamine (data not shown). In addition, serum from one animal given $2.0 \mathrm{mg}$ deferoxamine with CVF showed that, by $30 \mathrm{~min}, 59 \%$ of the $\mathrm{C} 3$ was in the converted form as compared with $58 \%$ conversion of $\mathrm{C} 3$ in serum of a rat not given deferoxamine but otherwise treated similarly. These data indicate that the protective ef- fects of deferoxamine are not related to interference with complement activation.

In studies to be reported elsewhere, the addition of

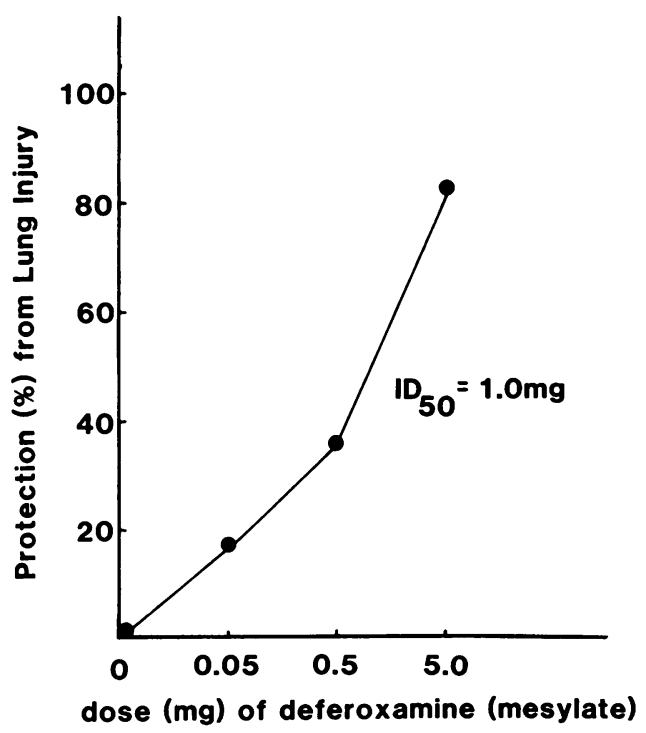

Figure 6 Protection by deferoxamine from acute lung injury after systemic complement activation due to CVF. Protection is dose related to the amount of deferoxamine infused. 
deferoxamine (in concentrations as high as $1.0 \mathrm{mM}$ ) to suspensions of rat neutropils failed to impair the chemotactic responses of these cells to complementactivated rat serum (G. O. Till, $H$. Tvedten, and P. A. Ward; paper to be submitted). These findings suggest that the in vivo protective effects of deferoxamine cannot be explained by a blocking of neutrophil activation.

Protective effects of DMSO on CVF-induced lung injury. In view of the known potent effects of DMSO as a hydroxyl radical scavenger (12), a series of rats was injected intraperitoneally with $1.0 \mathrm{ml}$ DMSO 10 min before intravenous injection of CVF. As shown in experiment A (Table IV), treatment of rats with DMSO (in the absence of CVF) had no lung-damaging properties; the mean lung permeability value for this group was $0.18 \pm 0.03$, as compared with animals treated with saline alone, with a mean lung permeability value of $0.21 \pm 0.02$. When animals were treated with CVF in the presence of DMSO, there was a substantial fall in the amount of lung injury (66\% protection, Table IV) as compared with animals treated only with CVF.

In another series of studies (Table IV, experiment B), the protective effects of DMSO on CVF-induced lung injury were again demonstrated. Animals infused only with saline exhibited the expected base-line values of lung permeability $(0.23 \pm 0.01)$, whereas infusion of CVF caused a fivefold increase in lung permeability $(1.17 \pm 0.21)$, whereas the pretreatment of rats with DMSO resulted in a considerable attenuation (73.4\%) of the lung injury, with a mean lung permeability value of $0.48 \pm 0.02$. Sera from these two animals protected with DMSO were analyzed for C3 conversion 5 min after infusion of CVF. These showed 49.2 and $49.3 \%$ conversion of $\mathrm{C} 3$, as determined by crossed immunoelectrophoresis. These data suggest that the protective effects of DMSO are not related to a blocking of the activation of the complement system after infusion of CVF. The data support the concept that $\mathrm{OH}^{\circ}$ generation may be a key event in the pathogenesis of lung damage after infusion of CVF.

In vitro chemotactic assays demonstrated that the presence of DMSO (in concentrations as high as 0.25 $M)$ in suspensions of rat neutrophils did not interfere with the chemotactic responses of these cells (data not shown). In studies of effects on $\mathrm{O}_{2}^{-}$generation, recent data also reveal that suspensions of rat neutrophils incubated with DMSO (0.1-0.001 M), deferoxamine (1 $\mathrm{mg} / \mathrm{ml})$, and apolactoferrin $(1.0 \mathrm{mg} / \mathrm{ml})$ produce as much $\mathrm{O}_{2}^{-}$after stimulation with $100 \mathrm{ng}$ phorbol myristate acetate as compared with cell suspensions similarly treated in the absence of these agents. Also, activation of neutrophils with $\mathrm{N}$-formyl-methionylleucyl-phenylalanine $\left(10^{-6} \mathrm{M}\right)$ in the presence of cytochalasin B $(5 \mu \mathrm{g} / \mathrm{ml})$ showed the same amounts of $\mathrm{O}_{2}^{-}$produced and lysozyme released in the presence or absence of the three agents listed above (G. O. Till, H. Tvedten, and P. A. Ward; paper to be submitted.). Thus, agents that protect against lung damage after intravascular activation of complement do not appear to be affecting generation of toxic oxygen products or release of lysosomal enzymes from activated neutrophils.

Morphological analysis of protected animals. Animals treated with CVF and killed $30 \mathrm{~min}$ later showed the expected morphological changes in lung. These findings were characterized by leukoaggregates within interstitial capillaries of lung and intraalveolar hemorrhage and fibrin deposits. At this magnification, there was also evidence of disruption of endothelial cells indicative of damage and/or destruction (Fig. 7 $A$, arrows). In animals injected with CVF and also treated with $1.0 \mathrm{ml}$ DMSO, aggregates of neutrophils were present within the interstitial capillaries, but

TABLE IV

Ability of DMSO to Protect from Acute Lung Injury

\begin{tabular}{|c|c|c|c|c|c|}
\hline \multirow[b]{2}{*}{$\begin{array}{l}\text { Experi- } \\
\text { ment }\end{array}$} & \multirow[b]{2}{*}{$\begin{array}{l}\text { Material injected } \\
\text { intravenously }\end{array}$} & \multirow[b]{2}{*}{ Intervention } & \multicolumn{2}{|c|}{ Lung permeability } & \multirow[b]{2}{*}{ Protection } \\
\hline & & & Individual values & Mean \pm SEM & \\
\hline & & & & & $\%$ \\
\hline \multirow[t]{5}{*}{ A } & Saline & None & $0.24,0.21,0.18$ & $0.21 \pm 0.02$ & - \\
\hline & Saline & $\mathrm{DMSO}^{\bullet}$ & $0.23,0.18,0.13$ & $0.18 \pm 0.03$ & - \\
\hline & CVF & None & $0.71,0.69,0.51,0.66,0.60$ & & \\
\hline & & & $0.65,0.89,0.70$ & $0.68 \pm 0.04$ & - \\
\hline & CVF & DMSO & $0.28,0.47,0.50,0.23$ & $0.37 \pm 0.06$ & 66.7 \\
\hline \multirow[t]{3}{*}{ B } & Saline & None & $0.26,0.21$ & $0.23 \pm 0.01$ & - \\
\hline & CVF & None & $1.37,0.96$ & $1.17 \pm 0.21$ & - \\
\hline & CVF & DMSO & $0.46,0.50$ & $0.48 \pm 0.02$ & 73.4 \\
\hline
\end{tabular}

- When used, $1.0 \mathrm{ml}$ DMSO was injected intraperitoneally $10 \mathrm{~min}$ before the vascular infusion of CVF or saline. 

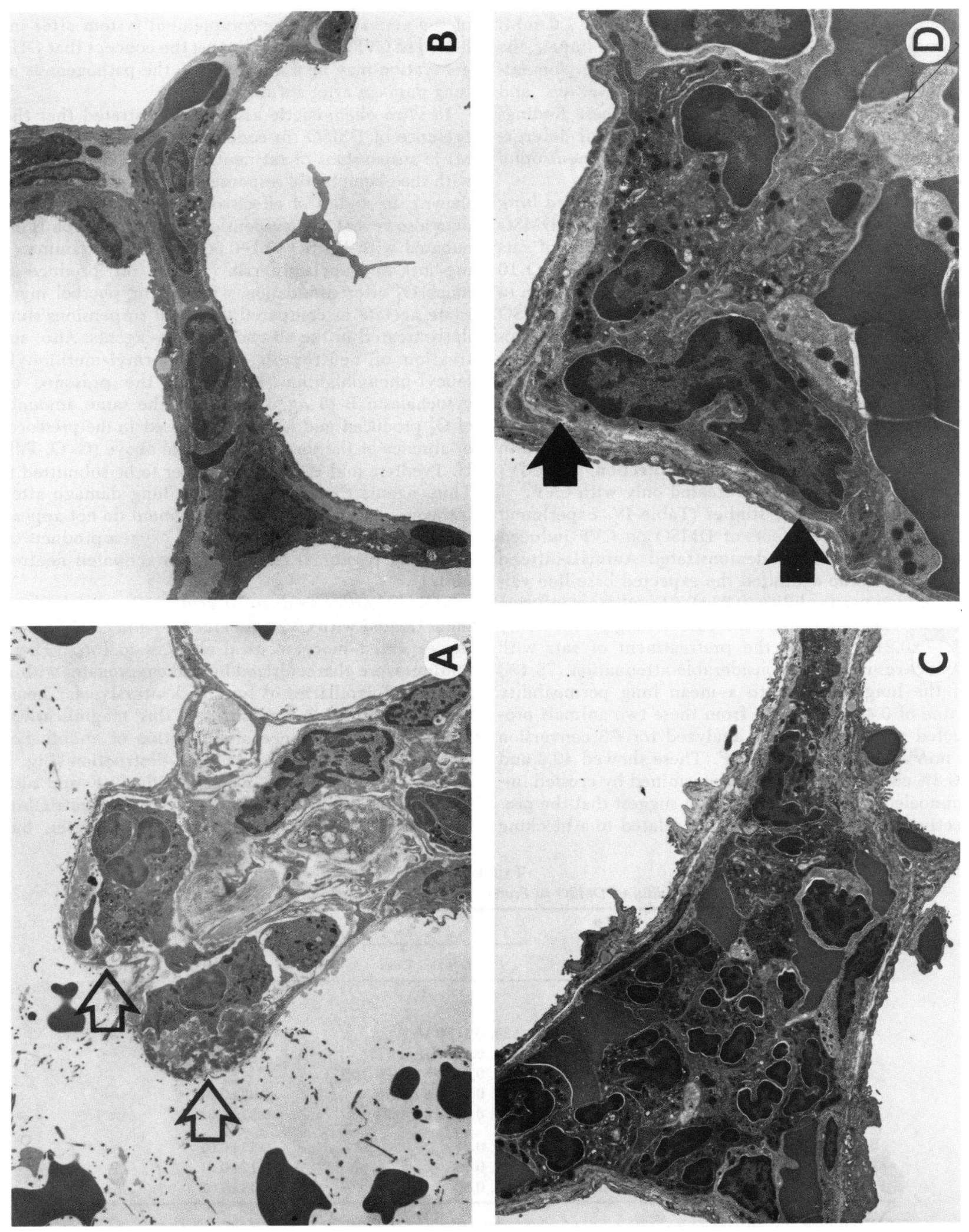

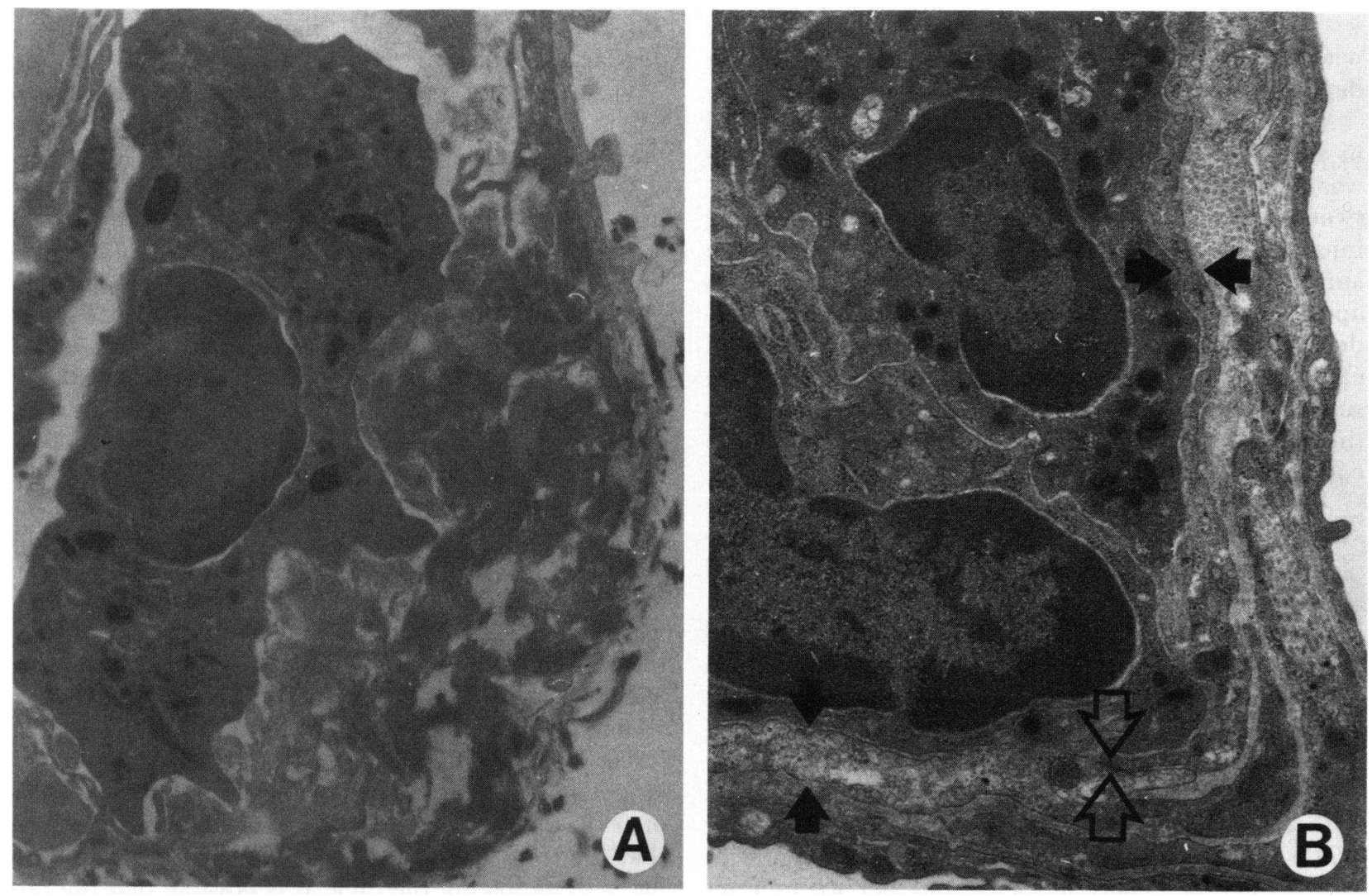

Figure 8 Higher magnifications of areas contained in Fig. $7 A$ and $D$. In frame $A$, from an animal injected with CVF, neutrophils are present within the capillary lumen and are in direct contact with proteinaceous debris and fibrin. There is loss of endothelial lining cells $(\times 14,000)$. In frame $B$, from an animal similarly treated but protected with apolactoferrin, a neutrophil is in direct contact with an intact endothelial cell (between solid arrows). No proteinaceous debris or fibrin is seen. An intact tight junction between endothelial cells is also present (open arrows). (X14,000).

there was no evidence of vascular damage. Endothelial cells were intact and hemorrhage and fibrin were absent (Fig. 7 B). In another group of animals treated with CVF as well as $2.0 \mathrm{mg}$ apolactoferrin (conditions leading to protection from lung injury, Table I), leukoaggregates were also apparent within the interstitial capillaries, but there was no evidence of hemorrhage or fibrin (Fig. $7 \mathrm{C}$ ). At a higher magnification, endothelial cells were intact. The vascular basement membrane was not exposed so as to be in direct contact with leukoaggregates (Fig. $7 D$ ), in contrast to the findings in Fig. $7 \mathrm{~A}$.

Under higher resolution, the areas in Fig. $7 \mathrm{~A}$ reveal complete disruption of the endothelial cell lining with evidence of amorphous proteinaceous debris adjacent to fibrin deposits, all of which abut against an exposed basement membrane on one side and an intravascular neutrophil on the other side (Fig. $8 \mathrm{~A}$ ). In contrast, a higher magnification of an area in Fig. $7 \mathrm{D}$ (from an apolactoferrin-protected animal) reveals a neutrophil

FIgURE 7 Transmission electron microscopic micrographs of rat lungs $30 \mathrm{~min}$ after intravenous infusion of CVF. In frame $A$, leukoaggregates are present within the interstitial capillaries of lung, along with intraalveolar hemorrhage and fibrin. There is also evidence of endothelial cell disruption (open arrows). In frame $B$, the animal also was treated with $2.0 \mathrm{ml}$ DMSO. Leukoaggregates are present in the interstitial capillaries but endothelial cells are intact and no evidence of intraalveolar hemorrhage or fibrin is present. In frames $C$ and $D$, sections of lungs from an animal injected with CVF and apolactoferrin $(2.0 \mathrm{mg})$ reveal changes similar to those described in frame $B$. In frame $D$, the endothelial cells show no evidence of damage (closed arrows). Magnification of frames $A, B, C$ is $\times 4,100$, while frame $D$ is $\times 10,500$. 
within the vascular compartment in direct contact with an intact endothelial cell lining (Fig. 8 B). Fibrin deposits and proteinaceous debris are absent.

Morphometric studies of lung tissues. As described in an earlier section, morphometric analysis of lungs was undertaken to assess quantitative differences between animals developing the full extent of acute lung injury after intravenous injection with CVF and those animals that had been protected by pretreatment with apolactoferrin (described above). Using plastic imbedded tissue sections, we examined the lung interstitial capillary and the alveolar compartments. The data are summarized in Table $\mathrm{V}$, where either linear distances (microns) reflecting surface areas or particle (cell) counts are recorded.

As is evident from the data, the interstitial capillary vessels in the saline-injected rats showed little evidence of bleb formation $(0.73 \pm 0.81 \mu \mathrm{m} / 174 \pm 38.4 \mu \mathrm{m}$ of total surface measured, or $0.41 \%$ of total surface area), whereas the CVF-treated animals showed a 30 -fold increase in the amount of bleb formation $(21.8 \pm 0.46$ $\mu \mathrm{m})$, which represented $17.9 \%$ of the entire capillary surface area $(121 \pm 12.2 \mu \mathrm{m})$ examined. In contrast, animals protected with apolactoferrin showed a greatly attenuated amount of vascular surface area involved with bleb formation $(2.1 \pm 0.99 \mu \mathrm{m} / 122.7 \pm 16 \mu \mathrm{m}$, or $1.72 \%$ of the total surface area being involved with bleb formation). There was a fivefold increase in numbers of neutrophils present within interstitial capillaries of CVF-treated rats as compared with rats treated with saline. For reasons that are not apparent, the animals treated with CVF and protective doses of apolactoferrin have nearly double the number of neutrophils within interstitial capillaries of the lung (Table V). As would be expected, for a given surface area of alveolar wall, there were few erythrocytes in tissues of rats injected intravenously with saline $(0.007$ erythrocytes/ $\mu \mathrm{m}$ alveolar wall) or with CVF and apolactoferrin $(0.003$ erythrocytes $/ \mu \mathrm{m}$ alveolar wall), whereas in the CVF-treated animals there were 0.058 eryth- rocytes/ $\mu \mathrm{m}$ alveolar wall (Table $\mathrm{V}$ ). Both the data dealing with bleb formation as well as those dealing with numbers of erythrocytes parallel the findings in which lung permeability changes were measured ( $\mathrm{Ta}$ ble I).

Potentiating effects of iron ion on CVF-induced lung injury. Since iron ion has a potentiating effect on the generation of hydroxyl radicals (13), rats were treated either with $\mathrm{Fe}^{3+}\left(\mathrm{FeCl}_{3}\right)$ or with $\mathrm{Fe}^{2+}$ $\left(\mathrm{Fe}\left[\mathrm{NH}_{4}\right]_{2}\left[\mathrm{SO}_{4}\right]_{2}\right)$ preparations together with CVF. As shown in Fig. 9, $\mathrm{Fe}^{3+}$ in a dose-dependent manner had a potentiating effect on the CVF-induced acute lung injury. With $0.6 \mathrm{nmol}$, there was a $15 \%$ enhancement of lung injury, whereas $6.0 \mathrm{nmol}$ produced a $67 \%$ increase in the amount of lung injury. With higher concentrations ( 30 and $60 \mathrm{nmol}$ ), there was a return towards the values for lung injury $(0.65 \pm 0.04)$ found in animals infused with CVF in the absence of iron salts. When a companion series of animals was studied, it was found that $\mathrm{Fe}^{2+}$ also caused enhancement of lung injury, but the enhancing effects were quantitatively less than those found with $\mathrm{Fe}^{3+}$ (Fig. 9). The intravenous infusion into two groups of two rats each of either $6 \mathrm{nmol} \mathrm{FeCl}_{3}$ or $60 \mathrm{nmol} \mathrm{Fe}\left(\mathrm{NH}_{4}\right)_{2}\left(\mathrm{SO}_{4}\right)_{2}$ in the absence of CVF resulted in lung permeability values of $0.12 \pm 0.02$ and $0.12 \pm 0.03$, respectively, indicating that the iron salts in these concentrations are not capable of damaging the lung. It is possible that the relatively limited ability of $\mathrm{Fe}^{2+}$ to potentiate lung injury was due to partial oxidation of $\mathrm{Fe}^{2+}$ to $\mathrm{Fe}^{3+}$.

\section{DISCUSSION}

In earlier studies, we demonstrated that infusion into rats of the $\mathrm{C} 3$ activator (isolated from cobra venom) results in acute lung vascular injury and that this injury depends on the availability of neutrophils and production of superoxide anion $\left(\mathrm{O}_{2}^{-}\right)$and $\mathrm{H}_{2} \mathrm{O}_{2}(5)$. We obtained direct morphological evidence of pulmonary vascular (capillary) endothelial cell injury, which was

TABLE V

Morphometric Measurements of Lung Sections

\begin{tabular}{|c|c|c|c|c|c|c|}
\hline \multirow[b]{2}{*}{ Treatment of animals } & \multirow[b]{2}{*}{ Sections } & \multicolumn{3}{|c|}{ Interstitial capillaries } & \multicolumn{2}{|c|}{ Alveoli } \\
\hline & & $\begin{array}{c}\text { Surface distance } \\
\text { containing endothelial blebs }\end{array}$ & Neutrophils & $\begin{array}{c}\text { Total endothelial } \\
\text { surface distance measured }\end{array}$ & Erythrocytes & $\begin{array}{c}\text { Total surface } \\
\text { distance } \\
\text { measured }\end{array}$ \\
\hline & $n$ & $\mu m$ & $n /$ capillary & $\mu m$ & n/alveolus & $\mu m$ \\
\hline Saline & 6 & $0.73 \pm 0.81$ & $0.33 \pm 0.21$ & $174.0 \pm 38.4$ & $1.8 \pm 1.2$ & $263.0 \pm 23.8$ \\
\hline CVF & 21 & $21.8 \pm 0.46$ & $1.6 \pm 0.49$ & $121.4 \pm 12.2$ & $10.7 \pm 2.4$ & $182.6 \pm 12.9$ \\
\hline $\mathrm{CVF}+$ apolactoferrin & 15 & $2.10 \pm 0.99$ & $3.6 \pm 0.87$ & $122.2 \pm 16.1$ & $0.7 \pm 0.39$ & $240.6 \pm 17.4$ \\
\hline
\end{tabular}

- Sections from four animals were examined in each group. 


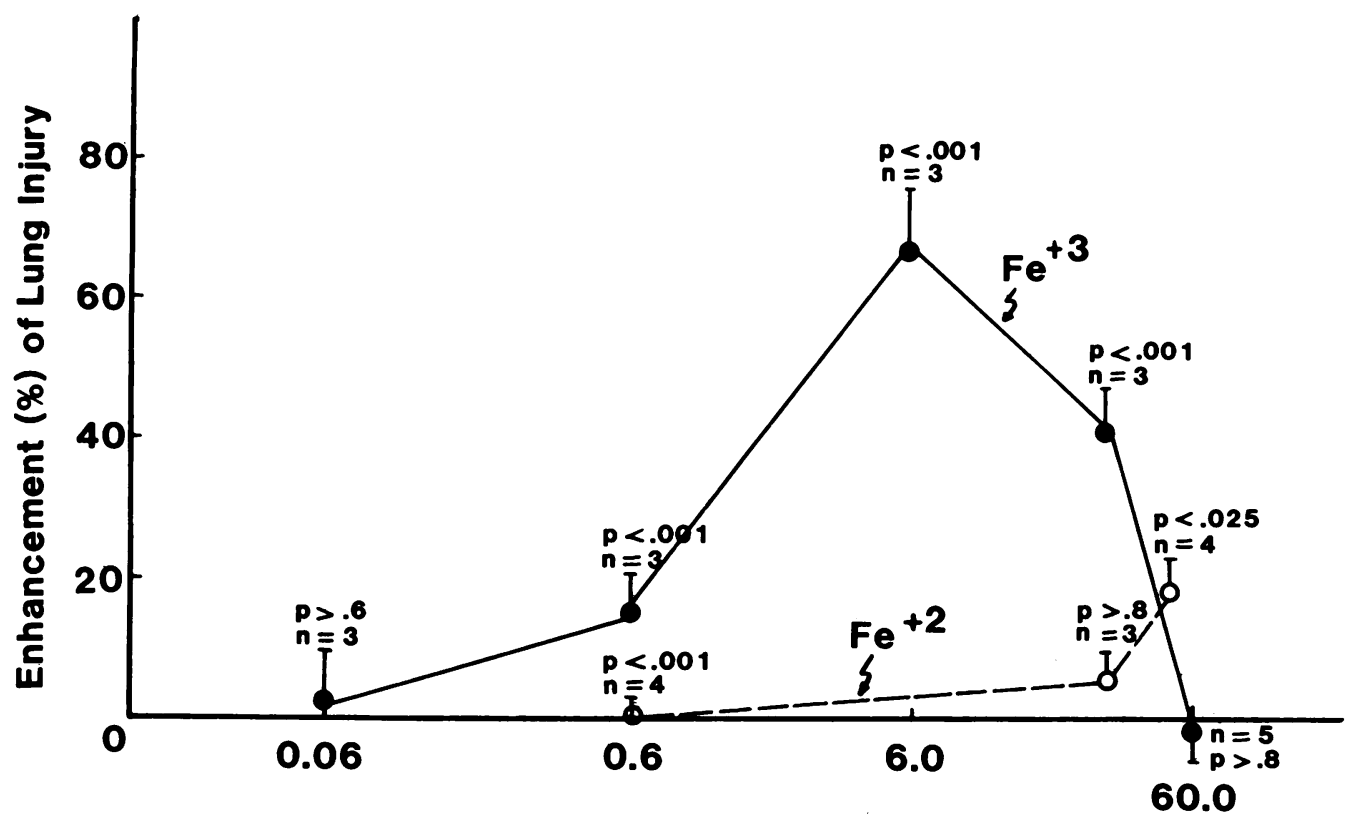

\section{nmoles iron salt}

Figure 9 Potentiation of acute lung injury by iron salts after infusion of CVF. $\mathrm{Fe}^{3+}$ causes substantial enhancement of lung injury when $6.0 \mathrm{nmol}$ are infused intravenously. The effect is dose dependent; at higher concentrations the enhancing effect is lost. $\mathrm{Fe}^{2+}$ also has potentiating effects that were substantially less than those of $\mathrm{Fe}^{3+}$. Significance $(P$ value) of each point is relative to the base line, which was determined by reference positive control values obtained in eight animals injected with CVF in the absence of iron salts.

always in proximity to leukoaggregates within capillaries. The mechanism responsible for the injury of endothelial cells was related to the generation of $\mathrm{O}_{2}^{-}$ and $\mathrm{H}_{2} \mathrm{O}_{2}$, but it was difficult to determine further the nature of the toxic oxygen products from activated neutrophils. Through manipulations that increase or decrease available ionic iron and by the use of a potent scavenger of $\mathrm{OH}^{\cdot}$, namely DMSO, evidence has now accumulated that strongly implies a role for $\mathrm{OH}^{\circ}$ in the pathogenesis of the tissue damage.

It has been known for some time that iron has the ability, through its role as a redox agent, to alter the nature of oxygen metabolites derived from leukocytes or from other sources $(3,13)$. The manner by which iron potentiates oxygen-related toxicity may be related to the following scheme:

$$
\begin{aligned}
\mathrm{O}_{2}^{+}+\mathrm{Fe}^{3+} & \rightarrow \mathrm{O}_{2}+\mathrm{Fe}^{2+} \\
\mathrm{Fe}^{2+}+\mathrm{H}_{2} \mathrm{O}_{2} & \rightarrow \mathrm{Fe}^{3+}+\mathrm{OH}^{\cdot}+\mathrm{OH}^{-}
\end{aligned}
$$

(Fenton reaction)

$$
\mathrm{O}_{2}^{-}+\mathrm{H}_{2} \mathrm{O}_{2} \rightarrow \mathrm{O}_{2}+\mathrm{OH}^{\cdot}+\mathrm{OH}^{-}
$$

(Haber Weiss reaction).
There is accumulating evidence that the reaction originally described by Haber and Weiss and first demonstrated in a physiological system by Beauchamp and Fridovich (14) and extended by observations of McCord and Day (15) is catalyzed in the presence of iron, either $\mathrm{Fe}^{2+}$ or $\mathrm{Fe}^{3+}$ (reviewed, 16). The scheme in reactions $A$ and $B$ seems to be a likely version of the actual reaction sequence. The generation of $\mathrm{OH}^{*}$ has been intimately linked with associated peroxidation of lipids, as measured by release of malondialdehyde, ethane, or ethylene. Recently Gutteridge (17) has demonstrated that liposomes incubated in the presence of ascorbate and $\mathrm{Fe}^{3+}$ will undergo lipid peroxidation (as measured by generation of products reactive with thiobarbituric acid), that this reaction can be inhibited by the presence of apolactoferrin but not by iron-saturated lactoferrin, and that it is inhibited by deferoxamine or by iron-poor transferrin. Ambruso and Johnston (18) have demonstrated that iron-saturated lactoferrin (either from human breast milk or leukocytes) enhances $\mathrm{OH}^{*}$ generation by neutrophils, whereas iron-poor preparations of lactoferrin are much less (one-half to one-third) effective. A direct correlation between these observations and evidence (C) of lipid peroxidation (as measured by ethylene pro- 
duction) was also noted. These observations, together with the findings from Repine et al. (19) and Murray and Cohn (20) that generation of $\mathrm{OH}^{-}$by neutrophils is a major factor in the killing of microbes engulfed by phagocytic cells, suggest that $\mathrm{OH}^{*}$ production is essential both in microbicidal activity as well as in leukocyte-dependent injury of tissues during the acute inflammatory response.

The ability of $\mathrm{Fe}^{3+}$ salts to potentiate lung injury stands in contrast to the very limited ability of $\mathrm{Fe}^{2+}$ to do the same (Fig. 9). Although the explanation for this observation is not apparent, a recent study by Bucher et al. (21) reviews current concepts and puts forward a new idea. Ferrous autoxidation will yield reduced oxygen species $\left(\mathrm{O}_{2}^{-}, \mathrm{H}_{2} \mathrm{O}_{2}, \mathrm{OH}^{*}\right)$ but this reaction is slow (21). The authors report that lipid peroxidation occurs in the presence of chelated ferrous ion, but that the process requires the addition of ferric ion. It is proposed that a ferrous-dioxygen-ferric complex is the initiating factor in lipid peroxidation. Somewhat unexpectedly, their studies failed to provide evidence for the role of reduced oxygen species participating in the reaction sequence, since the addition of oxyradical scavengers (mannitol, superoxide dismutase, catalase) did not reduce the extent of lipid peroxidation. Thus, a requirement for ferric ion in the events leading to acute lung injury may be related to the mechanism proposed by Bucher et al. (21), although lipid peroxidation would have to be assumed to be a key event involved in tissue damage, an assumption for which there is no direct evidence. In preliminary studies to determine whether iron levels of serum change in the course of developing acute lung injury after infusion of CVF, total serum iron before infusion of CVF into a rat was $1.76 \mu \mathrm{g} / \mathrm{ml}$ (determined by the ferrozine colorimetric method), of which free iron (measured in ultrafiltrates by the graphite furnace method) was $165 \mathrm{ng} / \mathrm{ml}$, indicating that $9 \%$ of the total iron was in the free form. $30 \mathrm{~min}$ after infusion of $\mathrm{CVF}$, the total iron was $2.09 \mu \mathrm{g} / \mathrm{ml}$, of which free iron was $347 \mathrm{ng} / \mathrm{ml}$, indicating a near doubling (to $17 \%$ ) in the amount of free iron in the serum. Although these data are preliminary, they suggest that free iron levels may increase in the course of CVF infusion, which could facilitate production of $\mathrm{OH}^{*}$ radical by the mechanisms described above.

Another reaction sequence related to $\mathrm{OH}^{*}$ generation and a microbicidal outcome has recently been suggested by Klebanoff (22), who described a bactericidal system dependent on the generation of $\mathrm{OH}^{*}$ and the presence of iodide and $\mathrm{Fe}^{2+}$. Scavengers of $\mathrm{OH}^{\cdot}$ interfered with the killing mechanism, which occurred at acidic $\mathrm{pH}$. It was presumed that an iodide derivative of $\mathrm{OH}^{*}$ was the toxic agent, although this has not been proven. Whether a similar mechanism may be involved in acute lung injury after systemic activation of the complement system is not presently known.

Toxicity of ionic iron in rats may also be related to an interplay with $\mathrm{H}_{2} \mathrm{O}_{2}$ or other oxygen metabolites. Dougherty et al. (23) have recently demonstrated that the toxic effects following injection of $\mathrm{Fe}^{2+}$ or $\mathrm{Fe}^{3+}$ into rats are directly proportional to ethane production (which is taken as a reflection of lipid peroxidation). The toxicity can be greatly potentiated by prior exposure of the animals to diets deficient in either selenium or vitamin $E$. These observations have been explained by the natural antioxidant activity of vita$\min \mathrm{E}$ and the requirement for selenium in the activity of glutathione peroxidase.

Finally, there is increasing evidence that generation of toxic oxygen products by leukocytes may be a crucial factor in complications arising during infectious diseases. Clark and Hunt (24) have recently shown that the massive destruction of erythrocytes occurring in mice infected with Plasmodia vinckei can be blocked by the prior infusion of deferoxamine. They interpret the data to suggest that parasite death and erythrocyte destruction may be mediated by generation of reactive oxygen species, such as $\mathrm{OH}^{\circ}$, and that this may be the reason for the destruction of nonparasitized erythrocytes and the endothelial cell damage that is known to occur in malaria. Indeed, the fact that substantial activation of the complement system is occurring in both plasmodial as well as babesial infections $(25,26)$ would be consistent with the idea that complement activation results in leukocytic activation, generation of $\mathrm{H}_{2} \mathrm{O}_{2}$, and its conversion in the presence of ionic iron to $\mathrm{OH}^{\circ}$, and tissue injury.

It should also be noted that lactoferrin has effects on several mediator systems. Oseas et al. (27) have recently suggested that leukocytic lactoferrin may play an important role in facilitating leukocytic adhesion to other leukocytes and to endothelial cells. This may be the reason for the ability of lactoferrin to cause a brief neutropenia when injected intravenously (11). Lactoferrin has also been described to block complement activation via the classical pathway (28), although this appears not to be relevant to the studies described above. Finally, lactoferrin appears to have the ability to facilitate or to diminish bactericidal activity of leukocytes (as referred to above), perhaps being directly related to its effects locally on the availability of ionic iron and thus the generation of $\mathrm{OH}^{*}$.

The studies in this report provide additional evidence for the role of toxic oxygen radicals by leukocytes activated in vivo by complement products and suggest that the conversion of $\mathrm{H}_{2} \mathrm{O}_{2}$ to $\mathrm{OH}^{-}$in the presence of ionic iron may be a key step in the ensuing tissue damage. These observations may have broad 
significance for tissue injury in a variety of conditions where complement activation products and neutrophils play a requisite role.

\section{ACKNOWLEDGMENTS}

The authors would like to thank Marty J. Lutz and Wallace Tourtellotte, Jr. for their excellent technical assistance during this study. We are also indebted to Dr. Felix de la Iglesia of the Warner Lambert Co. (Ann Arbor, MI) for his assistance in the morphometry studies.

This work was supported in part, by National Institutes of Health grants GM 28499, GM 29507, HL 28442, and HL 26809, a Veterans Administration Merit Review grant, and Council for Tobacco Research grant 1550.

\section{REFERENCES}

1. Ward, P. A., and C. G. Cochrane. 1965. Bound complement and immunologic injury of blood vessels. J. Exp. Med. 121:215-234.

2. Ward, P. A., T. E. Hugli, and D. E. Chenoweth. 1979. Complement and chemotaxis. In Chemical Messengers of the Inflammatory Process. J. C. Houck, editor. Elsevier/North-Holland Biomedical Press, Amsterdam. 153178.

3. Fantone, J. C., and P. A. Ward. 1982. A review: role of oxygen-derived free radicals and metabolites in leukocyte-dependent inflammatory reactions. Am. J. Pathol. 107:395-418.

4. Johnson, K. J., and P. A. Ward. 1981. Role of oxygen metabolites in immune complex injury of lung. J. Immunol. 126:2365-2369.

5. Till, G. O., K. J. Johnson, R. Kunkel, and P. A. Ward. 1982. Intravascular activation of complement and acute lung injury. Dependency on neutrophils and toxic oxygen metabolites. J. Clin. Invest. 69:1126-1135.

6. Bläckberg, L., and O. Hernell. 1980. Isolation of lactoferrin from human whey by a single chromatographic step. FEBS (Fed. Eur. Biochem. Soc.) Lett. 109:180-184.

7. Masson, P. L., and J. F. Heremans. 1968. Metal-combining properties of human lactoferrin (red milk protein). I. The involvement of bicarbonate in the reaction. Eur. J. Biochem. 6:579-584.

8. David, G. S., and R. A. Reisfeld. 1974. Protein iodination with solid state lactoperoxidase. Biochemistry. 13:10141021.

9. Beauchamp, C., S. Gonias, D. Menapace, and S. Pizzo. 1983. A new procedure for the synthesis of polyethylene glycol-protein adducts: effects on function, receptor recognition, and clearance of superoxide dismutase, lactoferrin and alpha ${ }_{2}$-macroglobulin. Anal. Biochem. 131:2533.

10. Clarke, M. H. G., and T. Freeman. 1968. Quantitative immunoelectrophoresis of human serum proteins. Clin. Sci. (Lond.). 35:403-407.

11. Boxer, L. A., B. Björksten, J. Björk, H.-H. Yang, J. M. Allen, and R. L. Baehner. 1982. Neutropenia induced by systemic infusion of lactoferrin. J. Lab. Clin. Med. 99:866-872.
12. Repine, J. E., J. W. Eaton, M. W. Anders, J. R. Hoidal, and R. B. Fox. 1979. Generation of hydroxyl radical by enzymes, chemicals, and human phagocytes in vitro. Detection with the anti-inflammatory agent, dimethyl sulfoxide. J. Clin. Invest. 64:1642-1651.

13. Haber, F., and J. Weiss. 1934. The catalytic decomposition of hydrogen peroxide in iron salts. Proc. R. Soc. (Lond.) A Math. Phys. Sci. 147A:332-351.

14. Beauchamp C., and I. Fridovich. 1970. A mechanism for the production of ethylene from methional: generation of the hydroxyl radical by xanthine oxidase. $J$. Biol. Chem. 245:4641-4646.

15. McCord, J. M., and E. D. Day, Jr. 1978. Superoxidedependent production of hydroxyl radical catalyzed by iron-EDTA complex. FEBS (Fed. Eur. Biochem. Soc.) Lett. 86:139-142.

16. Aust, S. D., and B. A. Svingen. 1982. The role of iron in enzymatic lipid peroxidation. In Free radicals in $\mathrm{Bi}$ ology. W. A. Pryor, editor. Academic Press, Inc., New York. 5:1-28.

17. Gutteridge, J. M. C. 1981. Inhibition of lipid peroxydation by the iron-binding protein lactoferrin. Biochem. J. 199:259-261.

18. Ambruso, D. R., and R. B. Johnston, Jr. 1981. Lactoferrin enhances hydroxyl radical production by human neutrophils, neutrophil particulate fractions, and an enzymatic generating system. J. Clin. Invest. 67:352-360.

19. Repine, J. E., R. B. Fox, and E. M. Berger. 1981. Hydrogen peroxide kills Staphylococcus aureus by reacting with staphylococcal iron to form hydroxyl radical. $J$. Biol. Chem. 256:7094-7099.

20. Murray, H. W., and Z. A. Cohn. 1979. Macrophage oxygen-dependent antimicrobial activity. I. Susceptibility of Toxoplasma gondii to oxygen intermediates. J. Exp. Med. 150:938-949.

21. Bucher, J. R., Tien, M. and S. D. Aust. 1983. The requirement for ferric ion in the initiation of lipid peroxidation by chelated ferrous iron. Biochem. Biophys. Res. Commun. 111:777-784.

22. Klebanoff, S. J. 1982. The iron $-\mathrm{H}_{2} \mathrm{O}_{2}$-iodide cytotoxic system. J. Exp. Med. 156:1262-1267.

23. Dougherty, J. J., W. A. Croft, and W. G. Hoekstra. 1981. Effects of ferrous-chloride and iron-dextran on lipid peroxidation in vivo in vitamin $E$ and selenium adequate and deficient rats. J. Nutr. 111:1784-1796.

24. Clark, I. A., and N. H. Hunt. 1983. Evidence for reactive oxygen intermediates causing hemolysis and parasite death in malaria. Infect. Immun. 39:1-6.

25. Fogel, B. J., A. E. von Doenhoff, Jr., N. R. Cooper, and E. H. Fife. 1969. Complement in acute experimental malaria. I. Total hemolytic activity. Mil. Med. 131:11731178.

26. Chapman, W. E., and P. A. Ward. 1976. The complement profile in babesiosis. J. Immunol. 117:935-938.

27. Oseas, R., H.-H. Yang, R. L., Baehner, and L. A. Boxer. 1981. Lactoferrin: a promoter of polymorphonuclear leukocyte adhesiveness. Blood. 57:939-945.

28. Kijlstra, A., and H. M. Jeurissen. 1982. Modulation of classical C3 convertase of complement by tear lactoferrin. Immunology. 47:263-270. 